ARTICLE

Received 17 Oct 2013 | Accepted 9 Jan 2014 | Published 5 Feb $2014 \quad$ DOl: 10.1038/ncomms4228

\title{
A non-canonical function of telomerase RNA in the regulation of developmental myelopoiesis in zebrafish
}

Francisca Alcaraz-Pérez¹,2, Jesús García-Castillo ${ }^{1,2, \star}$, Diana García-Moreno 1,2,3,* Azucena López-Muñoz 2,3, Monique Anchelin ${ }^{1,2}$, Diego Angosto ${ }^{2,3}$, Leonard I. Zon ${ }^{4,5,6}$, Victoriano Mulero ${ }^{2,3}$ \& María L. Cayuela ${ }^{1,2}$

Dyskeratosis congenita (DC) is an inherited disorder with mutations affecting telomerase or telomeric proteins. DC patients usually die of bone marrow failure. Here we show that genetic depletion of the telomerase RNA component (TR) in the zebrafish results in impaired myelopoiesis, despite normal development of haematopoietic stem cells (HSCs). The neutropenia caused by $T R$ depletion is independent of telomere length and telomerase activity. Genetic analysis shows that TR modulates the myeloid-erythroid fate decision by controlling the levels of the master myeloid and erythroid transcription factors spil and gata1, respectively. The alteration in spi1 and gata1 levels occurs through stimulation of gcsf and mcsf. Our model of TR deficiency in the zebrafish illuminates the non-canonical roles of $T R$, and could establish therapeutic targets for DC.

\footnotetext{
${ }^{1}$ Telomerase, Aging and Cancer Group, Research Unit, Department of Surgery, CIBERehd, University Hospital 'Virgen de la Arrixaca', 30120 Murcia, Spain. ${ }^{2}$ Instituto Murciano de Investigación Biosanitaria (IMIB), 30120 Murcia, Spain. ${ }^{3}$ Departamento de Biología Celular e Histología, Facultad de Biología, Universidad de Murcia, 30100 Murcia, Spain. ${ }^{4}$ Howard Hughes Medical Institute, Boston, Massachusetts 02115, USA. ${ }^{5}$ Stem Cell Program, Children's Hospital Boston, Boston, Massachusetts 02115, USA. ${ }^{6}$ Division of Hematology/Oncology, Children's Hospital Boston, Harvard Stem Cell Institute, Harvard Medical School, Boston, Massachusetts 02115, USA. * These authors contributed equally to this work. Correspondence and requests for materials should be addressed to V.M. (email: vmulero@um.es) or to M.L.C. (email: marial.cayuela@carm.es).
} 
T elomerase is a RNA-dependent DNA polymerase that synthesizes telomeric repeats at the end of eukaryotic chromosomes ${ }^{1}$. This enzyme complex consists of a catalytic protein with a telomere-specific reverse transcriptase activity (TERT), an internal RNA template (TR) and a number of associated proteins ${ }^{2}$. Telomerase is essential for the lifelong maintenance of multiple cells, including haematopoietic stem cells (HSCs) ${ }^{3}$. Traditionally, telomerase alterations have been associated to cancer and aging. TERT, TR or both components are also involved in some rare human diseases. For example, heterozygous mutations of human TR and TERT genes have been described in patients with acquired aplastic anaemia and the autosomal dominant form of dyskeratosis congenita $(D C)^{4,5}$ and in patients with idiopathic pulmonary fibrosis ${ }^{6}$.

DC is an inherited disorder characterized by a variety of phenotypes but patients usually die of bone marrow failure ${ }^{7}$. DC patients show signs of premature aging and they are more susceptible to develop cancers. All DC patients have some defects in telomere biology and those defects affect the renewing capabilities of $\mathrm{HSCs}^{8,9}$. All mutations identified to date in DC patients are found in telomerase components or in telomere-stabilizing components ${ }^{7}$. Although mutations in both $T R$ and TERT genes act as autosomal dominant due to an haploinsufficiency of telomerase and show disease anticipation associated with progressive telomere shortening ${ }^{10}$, the presentation of the disease is more serious in patients with mutations affecting $T R^{7}$.

Besides its telomere-lengthening function, there is increasing evidence that TERT can have physiological roles that are independent of this central function in both mammals ${ }^{11-15}$ and zebrafish ${ }^{16}$. Zebrafish telomerase promotes the development of haematopoietic cells through a non-canonical mechanism that is independent of the authentic telomerase activity of TERT and the role of this enzyme in telomere lengthening ${ }^{16}$. The cancer-promoting activity of TR may occur independently of telomerase activity ${ }^{17-20}$. Although the mechanism involved in this activity of TR is largely unknown, a recent study identified 2,198 TR-binding sites in the genome using chromatin isolation by RNA purification (ChIRP), which represents a large resource to study potential non-canonical functions of $T R$ RNA and telomerase ${ }^{21}$. TR occupied multiple Wnt genes directly and several binding sites near the MYC gene, concordant with previously documented binding sites of TERT ${ }^{21}$.

In the present study, we have taken advantage of the easy genetic manipulation and transparency of zebrafish embryos, together with the availability of several transgenic lines with labelled blood cells, to identify a non-canonical role of $T R$. Genetic inhibition of $T R$ demonstrated normal emergence of HSCs, but there is an alteration of cell fate. The change in developmental myelopoiesis occurs through the regulation of the master myeloid and erythroid transcription factors spil and gata1. The alteration in levels of these transcription factors is controlled by the stimulation of granulocyte- and macrophage colony-stimulating factors. Telomere length in the TR-deficient animals is surprisingly normal. Our studies identify a cell fate change established by a non-canonical role for $T R$.

\section{Results}

TR deficiency impairs telomerase activity. To study the role of telomerase RNA component (TR) in haematopoiesis, we used antisense morpholino (MO)-mediated knockdown technology in zebrafish embryos. Three different MOs were designed, each one targeting a different domain of $T R$, namely the template, CR4/CR5 and ScaRNA domains (Fig. 1a, Supplementary Table 1). The efficiency of these MOs was assayed by quantitative telomeric repeat amplification protocol (Q-TRAP) (Fig. 1b), which has been reported to be a rapid and accurate assay for the quantification of

a

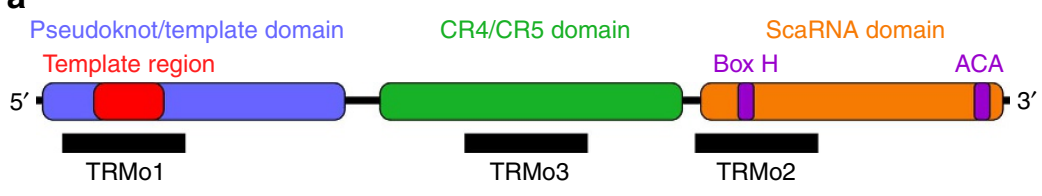

b

C
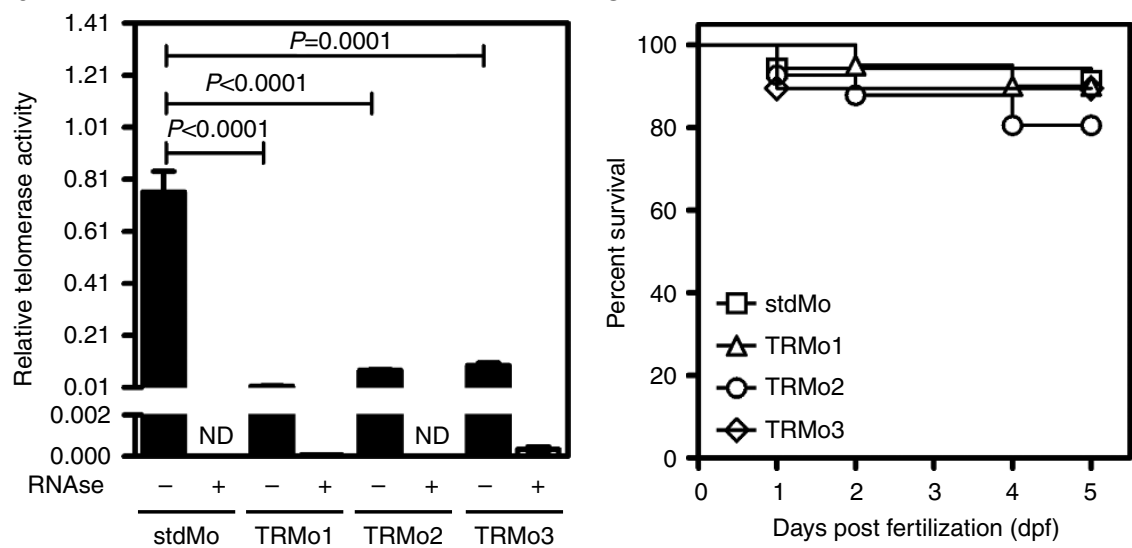

Figure 1 | TR deficiency impairs telomerase activity. (a) Scheme showing the location of the different MOs against zebrafish TR. The different domains are according to Xie et ll. $^{63}$ (b) Zebrafish embryos were microinjected at the one-cell stage with stdMo or the three different MOs against TR. At $3 \mathrm{dpf}$, telomerase activity was measured by Q-TRAP in 100 pooled zebrafish larvae using $1 \mu \mathrm{g}$ of protein extract. The specificity of the assay was confirmed using negative control samples that were treated with $1 \mu \mathrm{g}$ of RNAse at $37^{\circ} \mathrm{C}$ for 20 min. Results are expressed as the mean \pm s.e.m. from triplicate samples. Statistical significance was assessed using the Student's $t$-test $(P<0.05)$. ND: not detected. (c) Kaplan-Meier representation of the survival of three genetic backgrounds (stdMo, $n=35$; TRMo1, $n=20$; TRMo2, $n=41$; TRMo3, $n=38$ ). The survival curves were not statistically different, log rank test $P>0.05$. 
telomerase activity ${ }^{22}$. In each case, there was impaired telomerase activity, yet none of the MOs significantly affected zebrafish survival for up to 5 days (Fig. 1c) nor altered development (Supplementary Table 2).

TR deficiency induces neutropenia. Although $T R$ knockdown with three different MOs had no obvious effect on development, blood cell formation and circulation, we analysed in more detail the number of neutrophils at the caudal haematopoietic tissue $(\mathrm{CHT})$ at 3 days post fertilization (dpf) using a Tyramide Signal Amplification (TSA) staining assay for the detection of myeloperoxidase $(\mathrm{Mpx})^{23}$, which is a specific marker of zebrafish neutrophils ${ }^{24}$. Interestingly, the three $T R$ morphants showed a marked neutropenia compared with the control group (Fig. 2a and Supplementary Fig. 1). To rule out that TR deficiency directly affected the expression or activity of $\mathrm{Mpx}$, rather than neutrophil development and maintenance, we directly counted the number of lysozyme positive cells in the $\operatorname{tg}(l y z$ :DsRed $)$ line, which has red fluorescent neutrophils ${ }^{25}$, and neutropenia was evident (Fig. 2b). To examine whether macrophages were affected, a $\operatorname{tg}(m p e g 1: m C h e r r y)$ line was used that has red fluorescent macrophages ${ }^{26}$. The number of macrophages was also reduced in TR-deficient larvae (Fig. 2c).

We next examined myeloid cell activity in TR-deficient larvae. First, we performed a recruitment assay to study neutrophil a
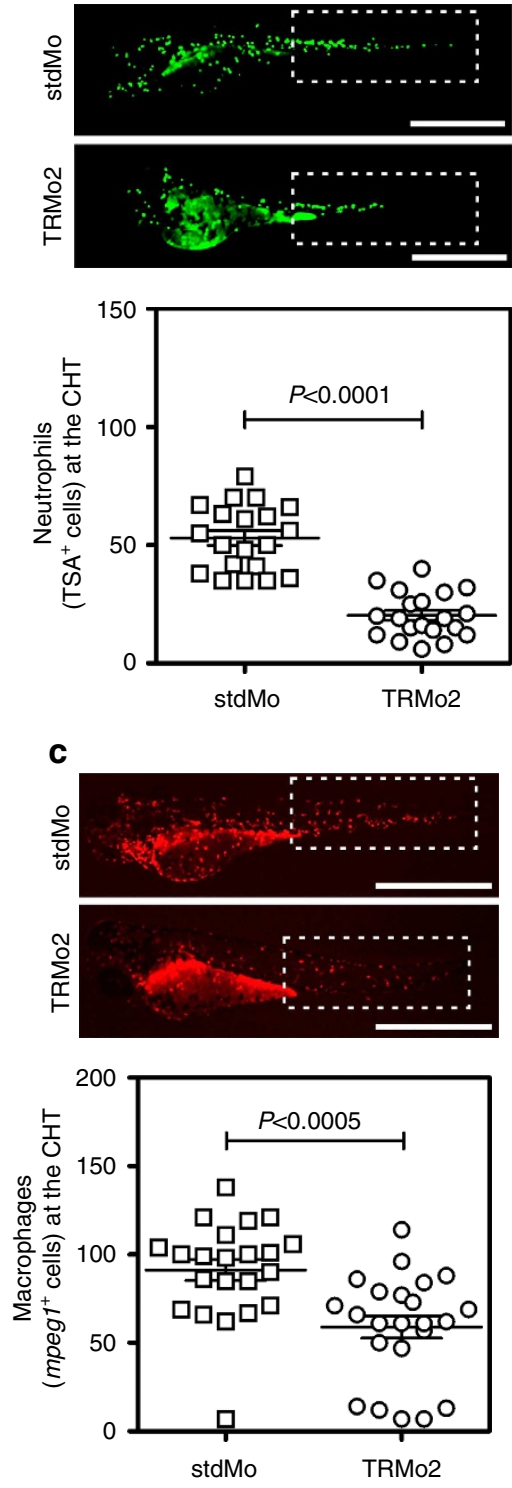

b
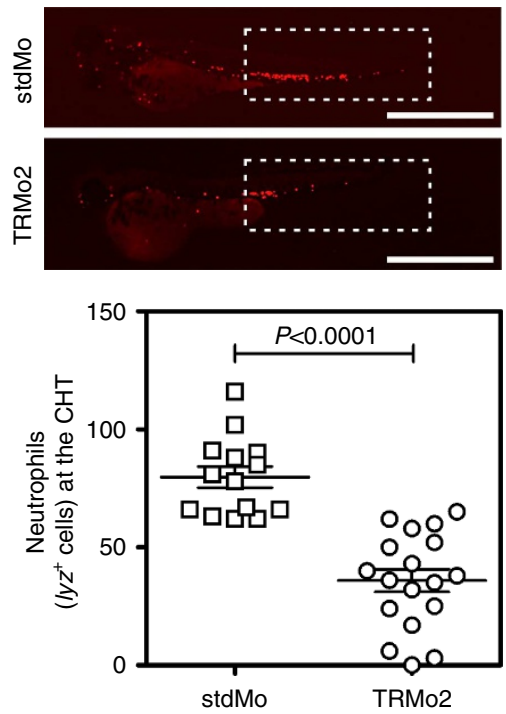

d
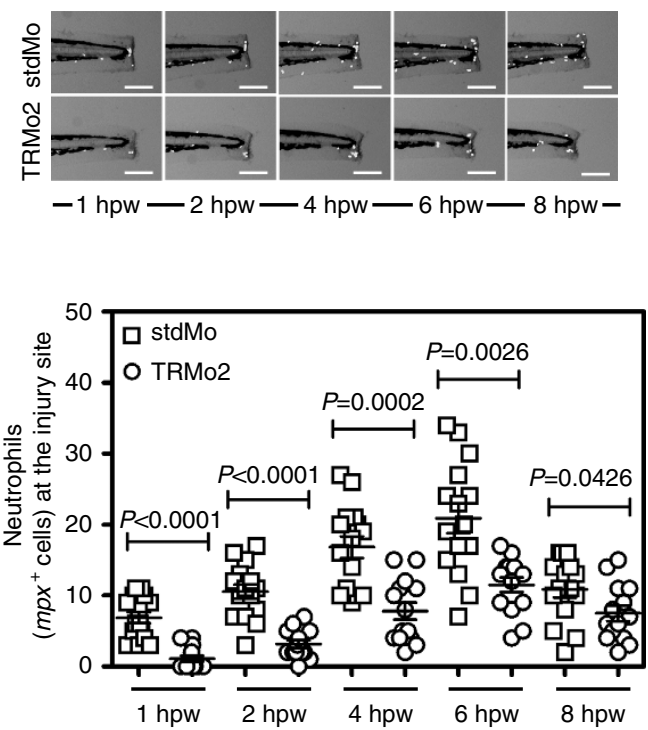

Figure 2 | TR deficiency induces neutropenia and monocytopenia but does not compromise neutrophil functionality. Zebrafish embryos were microinjected at the one-cell stage with stdMo or TRMo2. At 3 dpf, neutrophils were stained using the TSA kit (a) or directly visualized in Tg(lyz::DsRed) fish (b) by fluorescence microscopy and manually counted at the CHT. (c) Macrophages of $3 \mathrm{dpf} \operatorname{Tg}($ mpeg1::mCherry) were similarly visualized under fluorescence microscopy and counted at the CHT. (d) Tailfins of $\operatorname{Tg}(m p x::$ eGFP) std and TR morphants were transected at $3 \mathrm{dpf}$ and the number of fluorescent neutrophils visible in the tail was assessed by fluorescence microscopy. Positive cells in animals from both groups were visually quantified from high-quality pictures from an $8 \mathrm{~h}$ time series. Each symbol represents one larva and the mean \pm s.e.m. is also indicated. (a) stdMo, $n=20 ;$ TRMo2, $n=20$. (b) stdMo, $n=14$; TRMo2, $n=15$. (c) stdMo, $n=22$; TRMo2, $n=23$. (d) stdMo, $n=15$; TRMo2, $n=14$. Statistical significance was assessed using the Student's $t$-test $(P<0.05)$. Scale bars, $1 \mathrm{~mm}(\mathbf{a}-\mathbf{c})$ and $0.2 \mathrm{~mm}(\mathbf{d})$. hpw, hours post wounding. 
responses to an injury by tail fin transaction of $3 \mathrm{dpf} m p x:$ eGFP zebrafish larvae. Although the neutrophil number at the injury site was lower at all time points analysed in TR-deficient larvae, the kinetics of the recruitment was similar in both groups, being maximum at $6 \mathrm{~h}$ post injury (Fig. $2 \mathrm{~d}$ ), as previously described ${ }^{24}$. We next infected the larvae with the intracellular pathogenic bacterium $S$. typhimurium and found that the TR-deficient embryos showed similar resistance to infection with this bacterium (Supplementary Fig. 2a). Depletion of myeloid cells, that is, neutrophils and macrophages, using a MO against the master myeloid transcription factor spil (also known as pu.1) ${ }^{27}$ rendered larvae hypersusceptible to $S$. typhimurium infection (Supplementary Fig. 2a). In addition, TR-deficient larvae were also able to respond to $S$. typhimurium infection by upregulating the expression of the genes encoding the powerful proinflammatory cytokines IL-1 $\beta$ and $\mathrm{TNF} \alpha$, albeit at lower levels than their wild-type siblings (Supplementary Fig. 2b). Altogether, these observations establish that TR-deficient larvae have reduced number of neutrophils and macrophages, but that the cells that are present are fully functional.

$T R$ regulates myelopoiesis independently of telomere length. As the knockdown of TR by MOs resulted in the lack of telomerase activity, we wondered whether the use of $T R$ deficiency resulted in the shortening of telomere length, which may explain the observed phenotype. Telomere length was measured by quantitative-fluorescence in situ hybridization (Q-FISH) in interphasic blood cells collected from $3 \mathrm{dpf}$ larvae injected with stdMo and TRMo2. The results showed a similar telomere shortening, weak but significant, in TR- and TERT-deficient larvae (Fig. 3a and Supplementary Fig. 3a). In addition, the proportion of blood cells with short telomeres was similar in both groups of animals (Fig. 3a). Next, we wondered whether the neutropenia of TR-deficient larvae was related to the lack of telomerase activity. To accomplish this, we performed a TSA staining assay at $30 \mathrm{hpf}$ using a tert ${ }^{-/}-$zebrafish line, which lack telomerase activity ${ }^{28}$, and their tert ${ }^{+/+}$siblings. Although tertdeficient embryos showed normal number of neutrophils, the deficiency of $T R$ resulted in the reduction of neutrophils in both wild type and tert-deficient fish to a similar level, demonstrating that the loss of neutrophils was independent of telomerase activity (Fig. 3b).

The role played by $T R$ in myelopoiesis independently of telomerase activity prompted us to examine the expression of $T R$ and tert genes in sorted neutrophils ( $\mathrm{mpx}^{+}$cells) (Fig. $\left.3 \mathrm{c}\right)$. $T R$ RNA levels were strikingly higher in neutrophils than in unsorted cells, while tert mRNA was undetectable in neutrophils. Interestingly, the TRMo2 was able to strongly reduce the RNA levels of TR in unsorted cells and neutrophils but had no effect on tert mRNA levels (Fig. 3c). As expected, TR (Supplementary Fig. 3b) and tert (Supplementary Fig. 3c) genes were ubiquitously expressed during development, although tert was found to be expressed at higher levels by skin and neuromasts of $3 \mathrm{dpf}$ larvae. These results further suggest a non-canonical role of $T R$ in myelopoiesis.

$T R$ is required for myelopoiesis but dispensable for HSCs. To further determine the role of $T R$ in zebrafish definitive haematopoiesis, we analysed the expression of the specific haematopoietic genes lmo2, gata1a, spi1 (pu.1), gcsfr, cmyb, runx1 and rag1 by using whole-mount in situ hybridization (WISH) at different time points. The expression of $l m o 2$ and gatala, which are markers of erythromyeloid progenitors (EMPs) at $30 \mathrm{hpf}$ and are expressed in the posterior blood island $(\mathrm{PBI})^{29}$, was unaffected by $T R$ deficiency (Fig. 4a,b). The expression of spil and $g c s f r$, canonical markers of myeloid cells and neutrophils, respectively, was severely reduced at the PBI (Fig. 4c,d). This result was further confirmed with a TSA staining assay at $30 \mathrm{hpf}$, which showed the reduction of neutrophils $\left(\mathrm{mpx}^{+}\right.$cells) in $T R$ deficient embryos (Fig. 4e). The expression of cmyb and runx1 begin by $36 \mathrm{hpf}$ at the aorta-gonad-mesonephros (AGM) and they mark emerging definitive haematopoietic stem and progenitor cells ${ }^{30}$. Notably, the absence of $T R$ did not affect the expression of $c m y b$ and runx1 (Fig. 4f,g). This result was also verified using the $\operatorname{Tg}(c d 41:: \mathrm{eGFP})^{31}$, in which the number of $c d 41^{+}$cells (HSCs and thrombocytes) at $3 \mathrm{dpf}$ was independent of the presence of $T R$ (Fig. $4 \mathrm{~h}$ and Supplementary Fig. 4a). Similarly, the expression of gatala and rag1, which are expressed in erythrocytes and differentiated thymic T cells, respectively, was apparently unaffected by $T R$ deficiency (Fig. 4i,j). Similarly, o-dianisidine staining of the erythroid haemoglobin was also unaltered in TR-deficient embryos (Supplementary Fig. 4b). In sharp contrast, the expression of the myeloid markers spil (Fig. 4k,l) and gcsfr (Fig. 4m,n) was significantly reduced at this time. Collectively, these results suggest that although $T R$ is dispensable for the development of EMPs and HSCs in zebrafish embryos, it is required for the differentiation of neutrophils, and likely macrophages, from EMPs and HSCs.

To study whether myeloid progenitor differentiation was altered in the absence of $T R$, we stained blood cells collected by cardiac puncture from $2 \mathrm{dpf}$ embryos with Wright-Giemsa stain and observed alterations in blood cell morphology in TR-deficient embryos (Supplementary Fig. 5a). Thus, the blood cells from $T R$-deficient embryos showed statistically significant lower radius (Supplementary Fig. 5b) and higher nucleus/cytoplasm ratio (Supplementary Fig. 5c) than their wild-type siblings. These findings are consistent with a delay in differentiation.

TR deficiency alters the spil/gatala balance in blood cells. spil and gatal are both transcriptional factors essential for the differentiation of HSCs to myeloid and erythroid cells, respectively. The expression of $T R$, spil and gatala was analysed in the $\mathrm{CHT}$ of $2 \mathrm{dpf}$ embryos. The spil/gatala ratio was significantly reduced when $T R$ was depleted (Fig. 5a and Supplementary Fig. 6), usually because spil transcript levels decreased and those of gatala increased (Fig. 5b).

These results prompted us to investigate the impact of $T R$ overexpression in developmental myelopoiesis. The results showed that an in vitro-transcribed and capped TR RNA was able to rescue the number of neutrophils in $T R$ morphants at $3 \mathrm{dpf}$ (Fig. 5c), although it failed to significantly rescue the spil/gatala ratio (Fig. 5d and Supplementary Fig. 7a). We next studied the epistatic relationships between $T R$ and spil. Overexpression of spil RNA was also able to rescue the number of neutrophils (Fig. 5e) and the spil/gatala balance (Fig. 5f and Supplementary Fig. 7b). Similarly, depletion of gatala using a specific MO was also able to rescue the number of neutrophils (Fig. 5g) and the spil/gatala balance (Fig. 5h and Supplementary Fig. 7c). Our studies define a crucial role of $T R$ in maintaining a critical balance between the major myeloid (spi1) and erythroid (gata1a) transcription factors.

TR regulates the expression of $\boldsymbol{g c s} f$ and $\boldsymbol{m} \boldsymbol{c s f}$. A total of 2,198 $T R$-binding sites in the human genome have recently been identified, which represent a large resource to study potential non-canonical functions of TR RNA and telomerase ${ }^{21}$. Strikingly, TR occupied binding sites near CSF1 and CSF2 genes, which encode macrophage colony-stimulating factor (MCSF) and granulocyte-macrophage colony-stimulating factor (GMCSF), respectively. Although no orthologues for CSF2 gene have been 
a

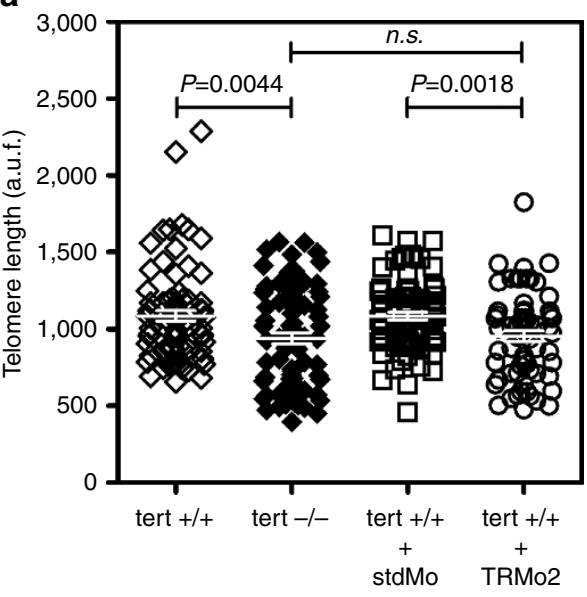

b
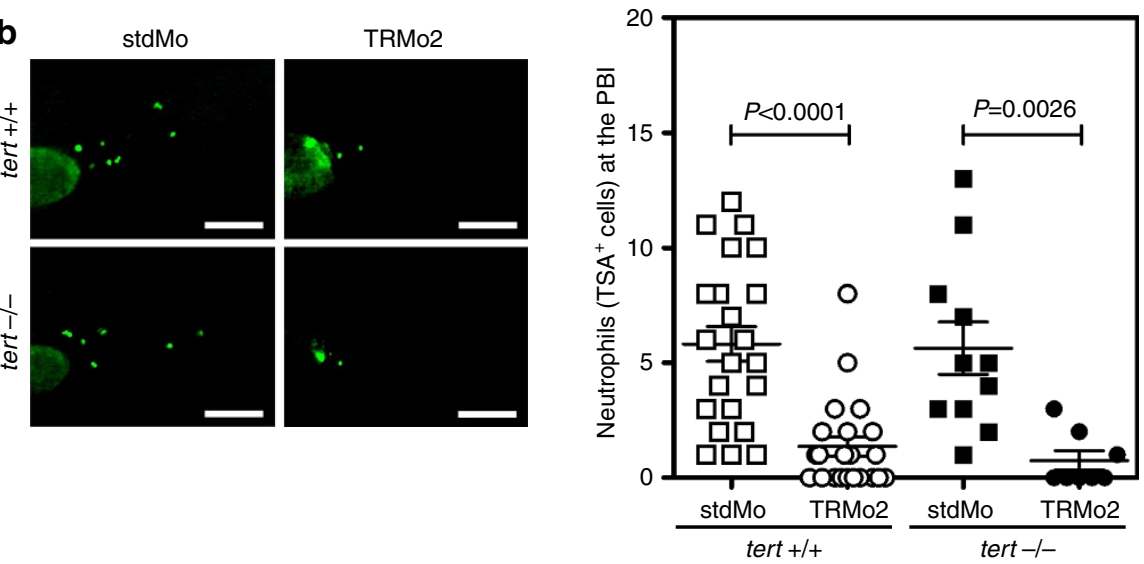

C
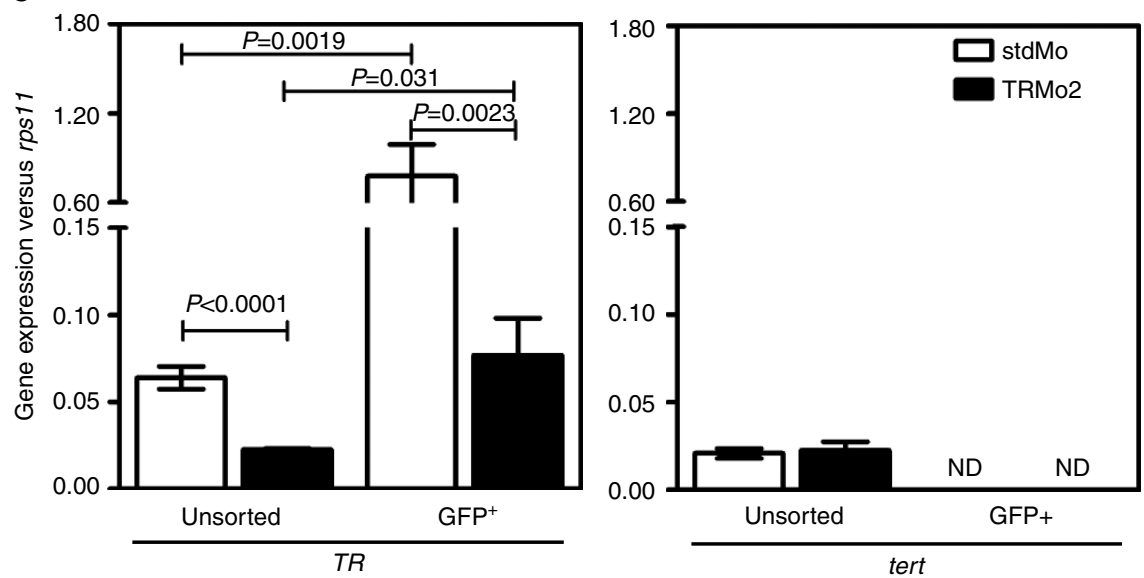

Figure 3 | The induction of neutropenia by TR depletion is independent of both telomere length and telomerase activity. Zebrafish embryos were microinjected at the one-cell stage with stdMo or TRMo2. (a) Telomere length was evaluated by Q-FISH in interphasic blood cells from 3 dpf larvae. Each symbol represents one cell and the mean \pm s.e.m. is also indicated. tert $+/+, n=80$; tert $-/-, n=83 ;$ stdMo, $n=85 ;$ TRMo2, $n=68$. Statistical significance was assessed using the Student's $t$-test $(P<0.05)$. (b) Neutrophils of tert $+/+$ and tert $-/-$ embryos were stained at 30 hpf using the TSA kit, visualized by fluorescence microscopy and manually counted at the PBI. Each symbol represents one embryo and the mean \pm s.e.m. is also indicated. tert $+/+$, std Mo, $n=22$; tert $+/+$, TRMo2, $n=22$; tert $-/-$, stdMo, $n=11$; tert $-/-$, TRMo2, $n=8$. Statistical significance was assessed using the Student's $t$-test $(P<0.05)$. (c) The mRNA levels of TR and tert was determined by RT-qPCR in unsorted versus neutrophils (mpx ${ }^{+}$) at $3 \mathrm{dpf}$. The graph shows the mean \pm s.e.m. of triplicate samples and is representative of three independent experiments. Statistical significance was assessed using the Student's $t$-test $(P<0.05)$. n.s., not significant; ND, not detected. Scale bars, $200 \mu \mathrm{m}$.

identified to date in zebrafish, true orthologues for CSF1 and CSF3, which encode GCSF, have been found and shown to stimulate the survival, proliferation and differentiation of neutrophil and macrophages, respectively ${ }^{32,33}$. We sought to determine whether $T R$ was able to regulate the expression of these important cytokines. TR-deficient larvae showed reduced mRNA levels of both $g c s f$ and $m c s f$ compared with wild-type siblings (Fig. 6a). Conversely, overexpression of TR RNA increased the 

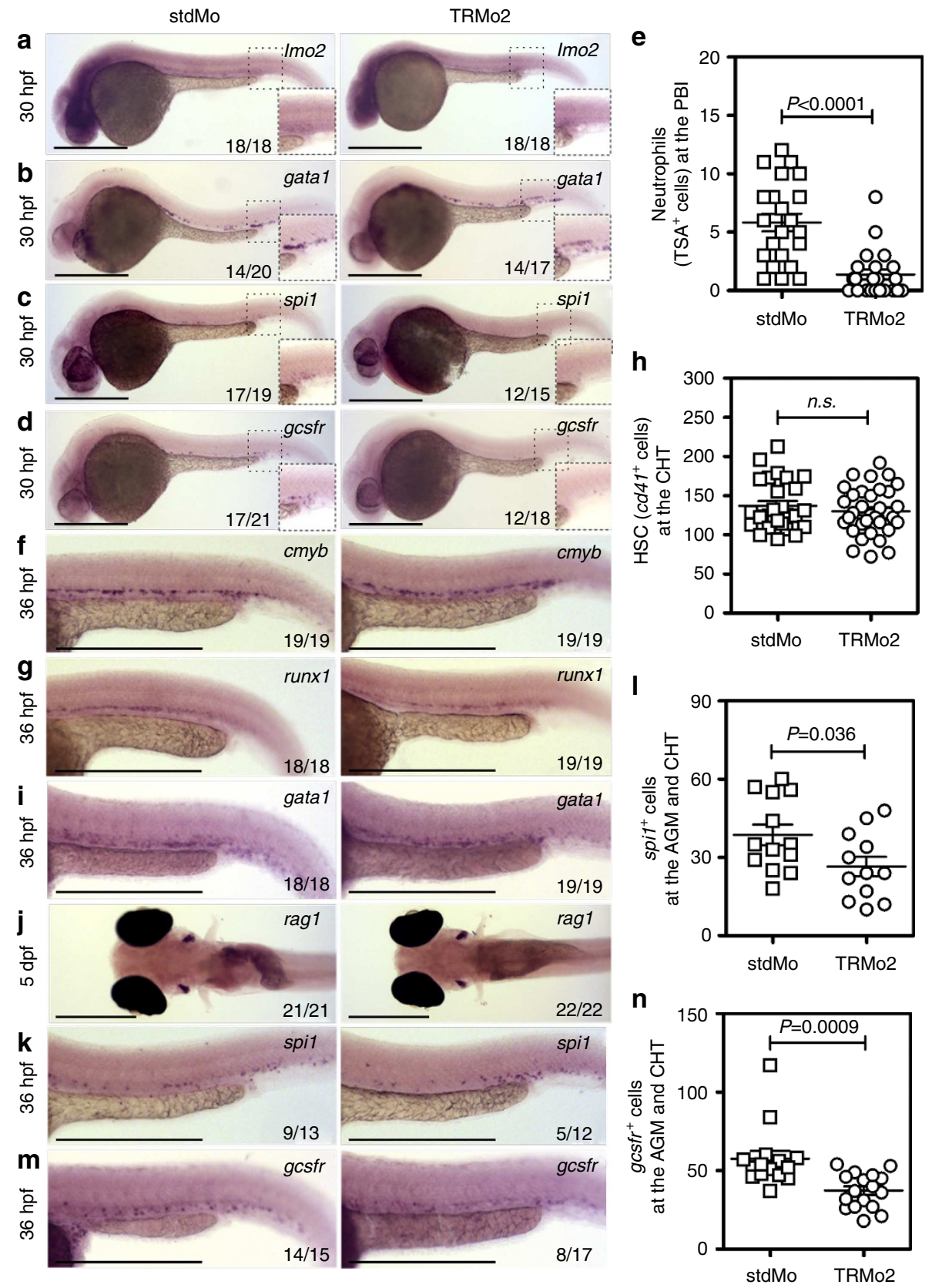

Figure 4 | TR is required for myelopoiesis but dispensable for the emergence of HSCs. Zebrafish embryos were microinjected at the one-cell stage with stdMo or TRMo2. At the indicated times, whole-mount in situ hybridization (WISH) was performed using antisense probes to the indicated haematopoietic genes. Scale bar, $0.5 \mathrm{~mm}$. (a-d) WISH of Imo2, gata1a, spil and gcsfr genes at $30 \mathrm{hpf}$. (e) Neutrophils were stained at $30 \mathrm{hpf}$ and visualized by fluorescence microscope and manually counted at the PBI. (f,g) WISH of cmyb and runx1 genes at 36 hpf. (h) The number of cd41+ cells of $\mathrm{Tg}(\mathrm{cd} 41:: \mathrm{eGFP})$ zebrafish were directly visualized by fluorescence microscopy at $3 \mathrm{dpf}$ and manually counted at the CHT. (i) WISH of gata1 at $36 \mathrm{hpf}$, rag1 at $5 \mathrm{dpf}(\mathbf{j})$ and spil at $36 \mathrm{hpf}(\mathbf{k})$. (I) Quantification of spi ${ }^{+}$cells at the AGM and CHT at $3 \mathrm{dpf}$. (m) WISH of gcsfr at $36 \mathrm{hpf}$ and (n) quantification of gcsfr ${ }^{+}$ cells at the AGM and CHT at $3 \mathrm{dpf}$. Numbers in pictures represent the animals with the shown phenotype per total analysed animals. Each symbol in graphs represents one embryo per larva and the mean \pm s.e.m. is also indicated. (e) stdMo, $n=22 ;$ TRMo2, $n=22$. (h) stdMo, $n=27 ;$ TRMo2, $n=34$. (I) stdMo, $n=13 ;$ TRMo2, $n=12$. (n) stdMo, $n=15 ;$ TRMo2, $n=17$. Statistical significance was assessed using the Student's $t$-test $(P<0.05)$. n.s., not significant.

transcript levels of both genes (Fig. 6b). Overexpression of gcsf (Fig. 6c) and mcsf (Fig. 6d) mRNAs rescued the number of neutrophils and macrophages, respectively. In addition, gcsf overexpression, and to some extent mcsf, increased spil expression levels, while they did not affect $T R$ levels (Supplementary Fig. 8a,b).

We next decided to use a luciferase reporter assay in whole zebrafish embryos, as we have previously described ${ }^{34}$. The results showed that TR deficiency inhibited, while $T R$ overexpression activated, gcsf promoter activity (Fig. 6e). Collectively, these results strongly suggest that $T R$ regulate the expression of $g c s f$ and $m c s f$ genes which maintain a critical balance between the major myeloid (spil) and erythroid (gata1) transcription factors.

\section{Discussion}

DC is an inherited disorder with mutations affecting telomerase components or telomere-stabilizing components, which is 
a

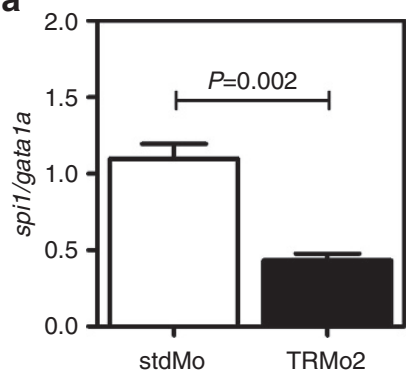

C

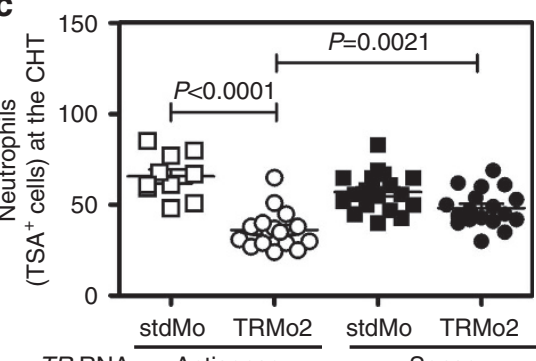

TR RNA Antisense Sense

e

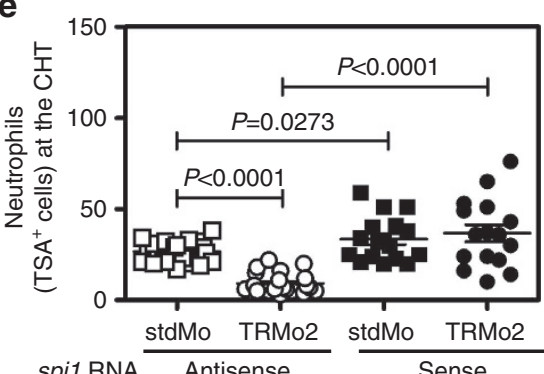

g

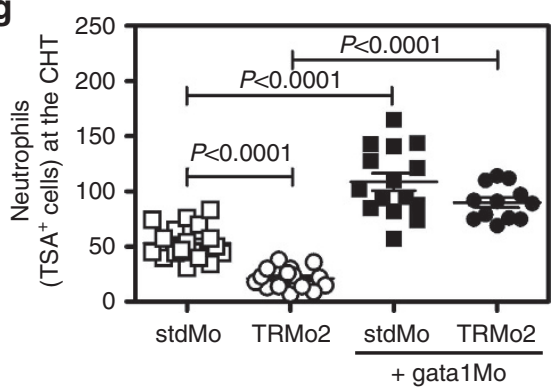

b

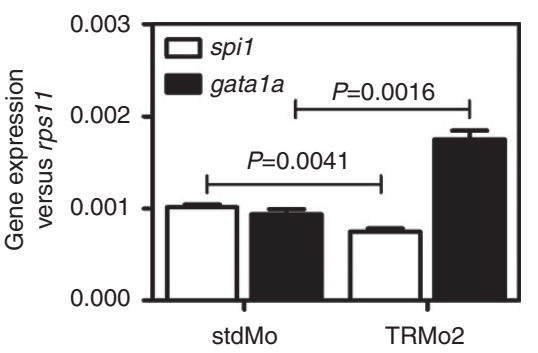

d

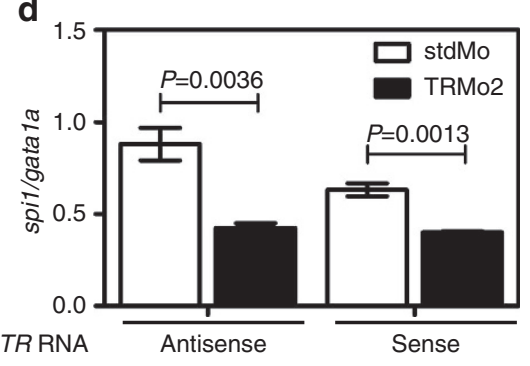

f

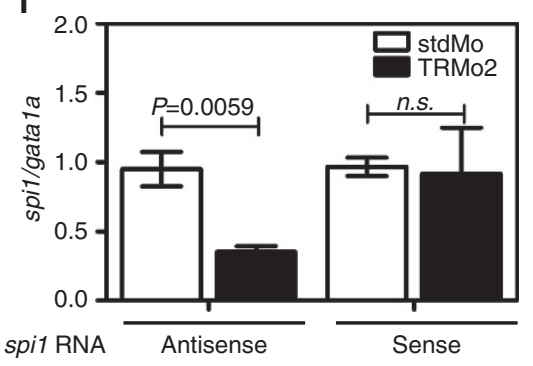

h

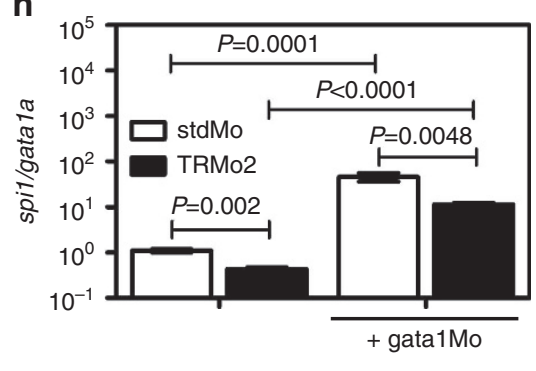

Figure 5 | TR deficiency alters the spi1/gata1a balance in blood cells. Zebrafish embryos were microinjected at the one-cell stage with stdMo, TRMo2 or gata1Mo alone or in combination with 50 (spil) or 200 (TR) pg/egg of in vitro-transcribed and CAP-modified antisense (as), TR and spi1 (sense, s) RNAs. (a) spil/gatala expression ratio (A) and mRNA levels (b) determined by RT-qPCR in tail sections of 2 dpf wild type. The graph shows the mean \pm s.e.m. of three independent experiments. $(\mathbf{c}, \mathbf{e}, \mathbf{g})$. Neutrophils were stained at $3 \mathrm{dpf}$ and visualized by fluorescence microscope and manually counted at the CHT. (d,f,h) spit/gatala expression ratio determined by RT-qPCR in tail sections of 2 dpf larvae. Each symbol represents one embryo and the mean \pm s.e.m. is also indicated. (c) stdMo, RNAas, $n=10$; TRMo2, RNAas, $n=16$; stdMo, RNAs, $n=18$; TRMo2, RNAs, $n=18$. (e) stdMo, RNAas, $n=21$; TRMo2, RNAas, $n=23$; stdMo, RNAs, $n=17$; TRMo2, RNAs, $n=16$. Statistical significance was assessed using the Student's $t$-test $(P<0.05)$. n.s., not significant.

characterized by a variety of phenotypes ${ }^{7}$. However, DC patients usually die of bone marrow failure due to a deficient renewing capability of $\mathrm{HSCs}^{8,9}$. Curiously, the presentation of the disease is more serious in patients with mutations affecting $T R^{7}$ and some mutations, such as $58 \mathrm{G} \rightarrow \mathrm{A}$, are not associated with impaired telomerase activity in vitro ${ }^{35}$. In addition, various lines of evidence have shown the cancer-promoting activity of $T R$ independently of telomerase activity ${ }^{17-20}$. All these observations, together with the ability of $T R$ to specifically bind 2,198 sites in the human genome $e^{21}$, led us to hypothesized that $T R$ plays a non-canonical role in haematopoiesis through the regulation of gene expression. We found that genetic depletion of $T R$ in zebrafish embryos with three different MOs resulted in a strong neutropenia and monocytopenia, which was fully rescued by the overexpression of $T R$ RNA, confirming the specificity of the observed phenotype. Strikingly, the effect of $T R$ in developmental myelopoiesis is independent of telomerase activity and telomere length, since tert mutant larvae showed normal number of neutrophils; TR depletion also led to neutropenia in tert mutant larvae; telomere length was weakly affected and to similar levels in 
a

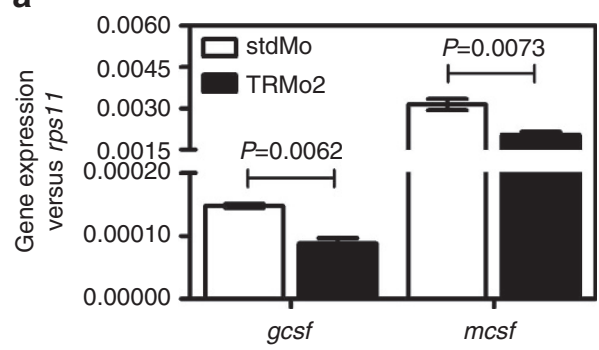

C

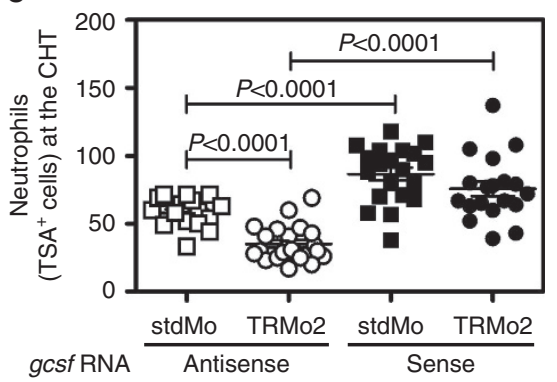

e

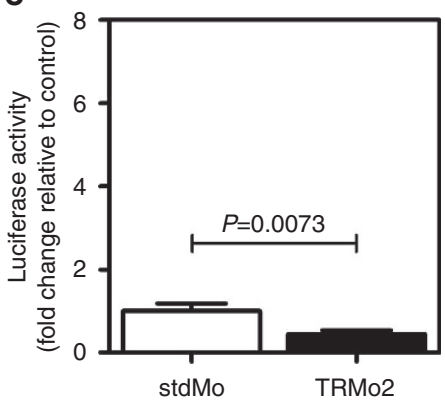

b

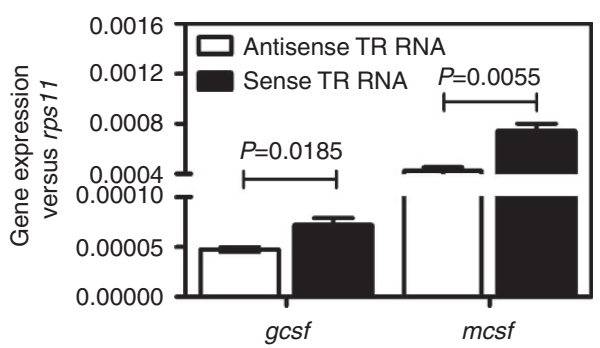

d

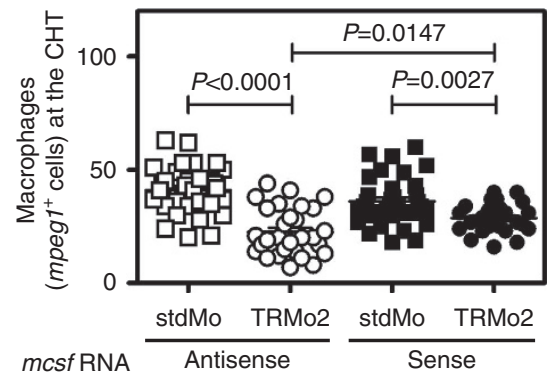

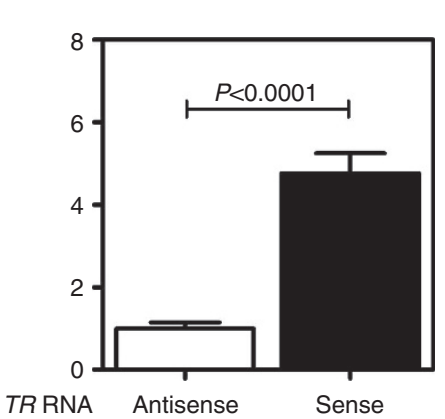

Figure 6 | TR regulates the expression of $\boldsymbol{g}$ csf and $\boldsymbol{m} \boldsymbol{c s f}$. Zebrafish embryos were microinjected at the one-cell stage with stdMo, TRMo2 (a-e), 100 pg per egg of in vitro-transcribed and CAP-modified antisense (as), gcsf (c) or mcsf (d) (sense, s) RNAs and/or a 20 pg/egg of gcsf::Luc and 2 pg/egg Renilla luciferase plasmids $(\mathbf{e}) .(\mathbf{a}, \mathbf{b})$ gcsf and mcsf expression analysed by RT-qPCR in tail sections of 2 dpf larvae. The graph shows the mean \pm s.e.m. of three independent experiments. (c,d) Neutrophils were stained at $3 \mathrm{dpf}$ using the TSA kit, visualized by fluorescence microscopy and manually counted at the CHT. Each symbol represents one embryo and the mean \pm s.e.m. is also indicated. (c) stdMo, RNAas, $n=17 ;$ TRMo2, RNAas, $n=22 ;$ stdMo, RNAs, $n=20$; TRMo2, RNAs, $n=19$. (d) stdMo, RNAas, $n=33$; TRMo2, RNAas, $n=30$; stdMo, RNAs, $n=35$; TRMo2, RNAs, $n=25$. (e) Luciferase activity in tail sections of $2 \mathrm{dpf}$ larvae. The graph shows the mean \pm s.e.m. of three independent experiments performed with triplicates samples. Statistical significance was assessed using the Student's $t$-test $(P<0.05)$.

$T R$ - and tert-deficient larvae; and $T R$ was expressed at very high levels in zebrafish neutrophils, while tert was undetectable in these cells. These results point to a non-canonical role of $T R$ in myelopoiesis and suggest its probable involvement in the regulation of neutrophil function. This apparent discrepancy with TR-deficient mice, which do not show impaired myelopoiesis independently of telomere shortening, may be due to developmental and/or physiological compensations, which probably do not exist in humans ${ }^{36-38}$.

$T R$-deficient neutrophils were recruited to wounds similarly to wild types. TR-deficient larvae did not show higher susceptibility to S. typhimurium and were able to upregulate $i l 1 b$ and tnfa genes at similar levels as wild types upon the infection. To the best of our knowledge, there is a single study on neutrophil function from DC patients ${ }^{39}$. This study showed that there was no significant difference in the degree of phorbol 12-myristate acetate (PMA) and N-formyl-methyonyl-leucyl-phenylalanine (fMLP)-triggered respiratory burst activity between 18 DC patients and their respective healthy family members. Unfortunately, the gene mutated in these patients was unknown and it is likely that there was a pool of patients with mutations affecting genes encoding different telomerase and/or telomere components. Our studies suggest that more DC patients should be examined for neutrophil defects.

One of the most interesting observations of our study is that definitive haematopoiesis was not affected in TR-deficient embryos. Thus, the expression of canonical markers for EMPs and HSCs seemed to be normal, as the number of $c d 41^{+}$cells at the CHT. Erythropoiesis and lymphopoiesis proceeded normally, further confirming that emergence, maintenance and differentiation of HSCs was unaffected in TR-deficient embryos. In contrast, TR-deficient embryos/larvae showed lower number of spil ${ }^{+}$and $g c s f r+$ cells, confirming that $T R$ is specifically required for the differentiation of myeloid cells, that is, neutrophils and macrophages. These results may explain the persistant neutropenia and altered myelopoiesis observed in DC children who showed normal erythropoiesis, megakaryopoiesis and normal lymphocyte subgroups and antibody levels ${ }^{40,41}$. We speculate that the critical role played by $T R$ in telomere maintenance might have masked its non-canonical role in myelopoiesis, since the majority of DC patients are examined at later stages of the disease when critically short 
telomeres severely impair HSC renewal and bone marrow failure is imminent.

Our in vivo genetic analysis provides the first experimental evidence to our knowledge that $T R$ modulates a critical gene regulatory network required for myelopoiesis, probably by regulating the expression of the two main growth factors involved in the differentiation of neutrophils (Gcsf) and macrophages (Mcsf). This is not unexpected since human $T R$ binds direct to both the CSF1 and CSF2 gene promoters ${ }^{21}$ and there is a complex crosstalk between mouse GCSF/GMCSF and SPI1 (refs 42-44). Therefore, TR could act as a positive transcription factor for these genes. Although the direct binding of TR to gcsf and $m c s f$ upstream regulatory sequences requires to be demonstrated, the subtle regulation of the zebrafish $g c s f$ gene promoter by $T R$ levels, assayed by a luciferase reporter assay in whole zebrafish larvae, supports this conclusion.

The regulation of spil and gatal genes in zebrafish has been shown to be critical for the differentiation of myeloid and erythroid cells. Reciprocal regulation of spil and gata1 determines myeloid versus erythroid fate ${ }^{27}$. In addition, loss of Gatal transforms primitive blood precursors into myeloid cells, resulting in a massive expansion of granulocytic neutrophils and macrophages at the expense of red blood cells ${ }^{45}$. Our results demonstrate that $T R$ modulates the myeloid versus erythroid fate outcomes from HSCs by differentially controlling the levels of spil and gatal via upregulation of $g c s f$ and mcsf. Intriguingly, transcription intermediate factor- $1 \gamma$ (tiflg, trim33) also plays a similar role by differentially controlling the levels of spil and gata1 (ref. 46)

The regulation of CSF genes by TR might have important clinical implications, since GCSF and GMCSF therapy has been used in DC patients to treat neutropenia ${ }^{47}$. It is tempting to speculate, therefore, that this therapy might be specifically efficient in DC patients carrying mutations in the TR gene before telomeres are critically short in HSC. While GCSF/GMCSF treatment has been found to be relatively effective in children ${ }^{40,41,48}$ and young adults with $\mathrm{DC}^{49,50}$, in other cases the treatment was only moderately effective in improving neutropoiesis ${ }^{51,52}$. Unfortunately, the mutation responsible for DC in all these clinical trials was unknown. The different efficiency of GSCF/GMCSF therapy may be related to the mutated gene and the telomere length of the patients. This speculation is supported by the ability of CD $34^{+}$cells from DC patients with a TR mutation to produce the different lineages of mature cells in normal numbers in vitro in response to growth factors, despite the HSC compartment of these patients being profoundly reduced ${ }^{53}$. Taken together, these results further indicate that telomere dysfunction of HSCs from DC patients or knockout mice might unmask the non-canonical role of $T R$.

In conclusion, this study provides experimental evidence that $T R$ plays a non-canonical role in the regulation of myelopoiesis by fine-tuning the expression of spil and gatal transcription factors in developing zebrafish embryos through the regulation of $g c s f$ and mcsf. The in vivo model developed here is a powerful tool to illuminate the non-canonical functions of TR in HSC emergence, maintenance and differentiation. In this way, further studies with this model could elaborate signalling pathways that are perturbed in DC patients and could represent therapeutic targets.

\footnotetext{
Methods

Ethics statement. The experiments performed comply with the Guidelines of the European Union Council (86/609/EU). Experiments and procedures were performed as approved by the Bioethical Committee of the University Hospital 'Virgen de la Arrixaca' (Spain) and by the Children's Hospital Boston institutional Animal Care and Use Committee (USA).
}

Animals. Zebrafish (Danio rerio H., Cypriniformes, Cyprinidae) were obtained from the Zebrafish International Resource Center and mated, staged, raised and processed as described ${ }^{54}$. The tert mutant line (allele hu3430) was obtained from the Sanger Institute and has been previously described ${ }^{28,55}$. The casper mutant ${ }^{56}$ and $\operatorname{Tg}(\text { gata } 1:: \mathrm{DsRed})^{57}$ lines were previously described. The transgenics lines $\operatorname{Tg}(\text { lyz::DsRed })^{25}, \operatorname{Tg}(m p x:: \text { GFP })^{24}, \operatorname{Tg}(m p e g 1:: G A L 4 /$ uas::NTRmCherry) (mpeg1::mCherry was used throughout this manuscript for clarity) ${ }^{26}$ and $\operatorname{Tg}(c d 41:: \mathrm{eGFP})^{31}$ were kindly provided by Drs P. Crosier, S. Renshaw, G. Lieschke and R.I. Handin, respectively.

Morpholino and RNA injection. Specific morpholinos (Gene Tools) were resuspended in nuclease-free water to $1 \mathrm{mM}$ (Supplementary Table 1). In vitro-transcribed RNA was obtained following the manufacturer's instructions (mMESSAGE mMACHINE kit, Ambion). Both morpholinos and mRNA were mixed in microinjection buffer $(0.5 \times$ Tango buffer and $0.05 \%$ phenol red solution) and microinjected into the yolk sac of one- to eight-cell-stage embryos using a microinjector Narishige IM300 (0.5-1 nl per embryo). The amount of injected RNA is indicated in each figure. The same amount of MOs and RNA were used in all experimental groups.

Analysis of development. The effect of MOs on development was evaluated as previously reported ${ }^{58}$. Briefly, the side-to-side flexures were recorded at 22 hpf (25-26 somites stage). The heartbeat, red blood cells on yolk and early pigmentation in retina and skin were recorded at $24 \mathrm{hpf}$ (Prim 5 stage). The head trunk angle (HTA), retina pigmentation, weak circulation, early touch reflect and, straight tail and caudal artery halfway to end of tail were recorded at $30 \mathrm{hpf}$ (Prim 15 stage). The early motility, tail pigmentation, strong circulation, and caudal artery $3 / 4$ of the way to the end of tail were recorded at $36 \mathrm{hpf}$ (Prim 30 stage).

Neutrophil staining. Zebrafish embryos of different ages were fixed overnight at $4{ }^{\circ} \mathrm{C}$ in $4 \%$ paraformaldehyde (PFA) and neutrophils were specifically stained by using the TSA-Plus Fluorescein kit (Perkin Elmer), following the manufacturer's instructions. Fluorescein-labelled neutrophils were then counted under an epifluorescence Lumar V12 stereomicroscope equipped with a digital camera (AxioCam MRm; Zeiss).

Embryo blood collection and staining. Blood cells were collected by cardiac puncture on anesthetized embryos in a solution of $0.02 \%$ tricaine (Sigma), 1\% BSA in PBS, pH 7.4. Collected cells were immediately spread on glass slides, allowed to air dry, fixed in methanol for $30 \mathrm{~s}$ and stained by the Wright-Giemsa method ${ }^{16}$.

o-dianisidine staining. Embryos were anesthetized with tricaine at $2 \mathrm{dpf}$ and stained with $1 \mathrm{mg} \mathrm{ml}^{-1} \mathrm{o}$-dianisidine (Sigma) in staining buffer (40\% ethanol, $10 \mathrm{mM} \mathrm{NaAc}, 0.675 \% \mathrm{H}_{2} \mathrm{O}_{2}$ ) for $15 \mathrm{~min}$ in the dark.

Flow cytometry. Approximately 100-200 embryos were dechorionated with pronase (Roche), mechanically dissociated between 30 and 36 hpf through 100 and $70 \mu \mathrm{m}$ cell strainers in $0.9 \times$ PBS solution supplemented with $10 \%$ fetal calf serum (FCS). Cell suspensions were analysed by fluorescence-activated cell sorting (FACS) using a BD FACSCanto flow cytometer. Data analyses were performed using BD FACSDiva 6.1.3 software (BD Biosciences).

Two- and 3-day $\operatorname{tg}(m p x:$ eGFP) larvae (300-600) were anesthetized in tricaine, minced with a razor blade, incubated at $28^{\circ} \mathrm{C}$ for $30 \mathrm{~min}$ with $0.077 \mathrm{mg} \mathrm{ml}^{-1}$ Liberase (Roche) and the resulting cell suspension passed through a $40-\mu \mathrm{m}$ cell strainer. eGFP ${ }^{+}$cells were then sorted using a staff-operated Beckman Coulter MoFlo Legacy Cell Sorter at the Bauer Core of the University of Harvard.

Telomerase activity assay. A real-time quantitative TRAP (Q-TRAP) analysis was performed ${ }^{22,59}$. Briefly, proteins were extracted from whole embryos/larvae using ice-cold NP-40 lysis buffer and real-time Q-TRAP performed with 0.1 and $1 \mu \mathrm{g}$ protein extracts. For making the standard curve, a 1:10 dilution series of telomerase-positive sample (HeLa cells) was used. Control samples were obtained by treating the cell extracts with $1 \mu \mathrm{g}$ RNase at $37^{\circ} \mathrm{C}$ for $20 \mathrm{~min}$. Data were collected and converted into Relative Telomerase Activity units performing the calculation: RTA of sample $=10^{\text {(Ct sample }-\gamma \text { int }) / s l o p e}$. The standard curve obtained was: $y=-3.2295 x+23.802$.

Q-FISH. Blood cells from 3 dpf larvae collected as described above were spread and hybridized with the PNA telomeric oligonucleotide (CCCTTA) 3 labelled with Cy3 (PE Biosystems) ${ }^{60}$. Cy3 and DAPI images were captured with $\times 100$ and $\times 60$ objectives respectively using a Nikon Digital Camera DXM 1200C on a Nikon Direct Eclipse fluorescence microscope. Telomere fluorescence signals were quantified using the TFL-TELO program (from Peter Lansdorp, Vancouver, Canada). 
Recruitment assay. At 3 dpf, mpx::GFP larvae were anesthetized in tricaine and complete transection of the tail was performed with a disposable sterile scalpel. Then, they were mounted in $1 \%(\mathrm{wt} / \mathrm{vol})$ low-melting-point agarose dissolved in egg water. The success of transection was confirmed immediately through an epifluorescence Lumar V12 stereomicroscope equipped with green fluorescent filters. Each fish image was captured and established as zero time. Thereafter, images were captured at the selected times while animals were kept in their aga matrixes with the added medium at $28.5^{\circ} \mathrm{C}$. All images were acquired with the integrated camera on the stereomicroscope and were used for subsequently counting the number of neutrophils recruited to the wound area, established between the arterio-venous loop and the end of the tail.

Bacterial infection assay. Larvae were infected with $\sim 10 \mathrm{CFU}$ per larva of wild-type strain 12023 of Salmonella enterica serovar Typhimurium (S. typhimurium) kindly provided by Professor D.W. Holden. Briefly, bacteria were injected in the Duct of Cuvier of 2 dpf larvae and then monitored every $24 \mathrm{~h}$ over a 5 -day period for clinical signs of disease and mortality ${ }^{61}$.

Whole-mount RNA in situ hybridization. Transparent Casper embryos were used for whole-mount RNA in situ hybridization ${ }^{62}$. lmo2, spil (pu.1), gatala, gcsfr, $c m y b$, runx 1, ragl, tert and $\operatorname{tr}$ RNA probes were generated using the DIG RNA Labelling Kit (Roche Applied Science) from linearized plasmids. Embryos were imaged using a Scope.A1 stereomicroscope equipped with a digital camera (AxioCam ICc 3, Zeiss).

Analysis of gene expression. Total RNA was extracted from whole embryos/ larvae or sorted cell suspensions with TRIzol reagent (Invitrogen) following the manufacturer's instructions and treated with DNase I, amplification grade (1 $\mathrm{U} \mu \mathrm{g}^{-1} \mathrm{RNA}$; Invitrogen). SuperScript III RNase $\mathrm{H}^{-}$Reverse Transcriptase (Invitrogen) was used to synthesize first-strand cDNA with oligo(dT) 18 (for all genes but $T R$ ) or R1 (for $T R$ ) primers from $1 \mu \mathrm{g}$ of total RNA at $50^{\circ} \mathrm{C}$ for $50 \mathrm{~min}$. Real-time PCR was performed with a MyiQ instrument (BIO-RAD) using SYBR Premix Ex Taq (Perfect Real Time; Takara). Reaction mixtures were incubated for $10 \mathrm{~min}$ at $95^{\circ} \mathrm{C}$, followed by 40 cycles of $15 \mathrm{~s}$ at $95^{\circ} \mathrm{C}, 1 \mathrm{~min}$ at $60^{\circ} \mathrm{C}$, and finally $15 \mathrm{~s}$ at $95^{\circ} \mathrm{C}, 1 \mathrm{~min}$ at $60^{\circ} \mathrm{C}$, and $15 \mathrm{~s}$ at $95^{\circ} \mathrm{C}$. For each zebrafish mRNA, gene expression was normalized to the ribosomal protein S11 content in each sample using the comparative $C t$ method $\left(2^{-\Delta \Delta} C t\right)$. The primers used are shown in Supplementary Table 3. In all cases, each PCR was performed with triplicate samples and repeated at least with two independent samples.

Analysis of gcsf gene promoter activity. A $2 \mathrm{~Kb}$ genomic DNA sequence upstream of $g c s f+1$ position was amplified using the following primers: forward $5^{\prime}$-CAGTGTTGTGGTTTTGGTCCAGGCG-3' ${ }^{\prime}$ and reverse $5^{\prime}$-CCGGA CACCGAGCACCGGCGAGCCGCC- $3^{\prime}$. The DNA fragment was cloned in the SmaI site of the pGL3basic vector (Promega) driving the expression of firefly luciferase gene ( $g c s f:$ Luc). One- to eight-cell-stage embryos were microinjected in the yolk with $0.5-1 \mathrm{nl}$ of a mix containing $20 \mathrm{ng} \mu^{-1}$ of the firefly luciferase construct, $2 \mathrm{ng} \mathrm{hl}^{-1}$ of Renilla luciferase control plasmid, $1 \mathrm{ng}$ per egg of stdMo and TRMo 2 or 200 pg per egg of in vitro-transcribed TR RNA. After $48 \mathrm{~h}$, tail sections of at least 50 larvae were obtained, pooled and assayed for luciferase activity using a Luminometer Optocomp I (MGM Instruments) ${ }^{34}$.

Statistical analysis. Data were analysed by analysis of variance (ANOVA). The differences between two samples were analysed by the Student's $t$-test. A log rank test was used to calculate the statistical differences in the survival of the different experimental groups.

\section{References}

1. Blackburn, E. H. Telomeres and telomerase: their mechanisms of action and the effects of altering their functions. FEBS Lett. 579, 859-862 (2005).

2. Hodes, R. J., Hathcock, K. S. \& Weng, N. P. Telomeres in T and B cells. Nat. Rev. Immunol. 2, 699-706 (2002).

3. Allsopp, R. C., Cheshier, S. \& Weissman, I. L. Telomerase activation and rejuvenation of telomere length in stimulated $\mathrm{T}$ cells derived from serially transplanted hematopoietic stem cells. J. Exp. Med. 196, 1427-1433 (2002).

4. Kirwan, M. \& Dokal, I. Dyskeratosis congenita, stem cells and telomeres. Biochim. Biophys. Acta 1792, 371-379 (2009).

5. Trahan, C. \& Dragon, F. Dyskeratosis congenita mutations in the H/ACA domain of human telomerase RNA affect its assembly into a pre-RNP. RNA. 15, 235-243 (2009)

6. Tsakiri, K. D. et al. Adult-onset pulmonary fibrosis caused by mutations in telomerase. Proc. Natl Acad. Sci. USA 104, 7552-7557 (2007).

7. Vulliamy, T. J. \& Dokal, I. Dyskeratosis congenita: the diverse clinical presentation of mutations in the telomerase complex. Biochimie 90, 122-130 (2008).
8. Brummendorf, T. H. \& Balabanov, S. Telomere length dynamics in normal hematopoiesis and in disease states characterized by increased stem cell turnover. Leukemia 20, 1706-1716 (2006).

9. Drummond, M. W., Balabanov, S., Holyoake, T. L. \& Brummendorf, T. H. Concise review: Telomere biology in normal and leukemic hematopoietic stem cells. Stem Cells 25, 1853-1861 (2007).

10. Vulliamy, T. et al. Disease anticipation is associated with progressive telomere shortening in families with dyskeratosis congenita due to mutations in TERC Nat. Genet. 36, 447-449 (2004)

11. Choi, J. et al. TERT promotes epithelial proliferation through transcriptional control of a Myc- and Wnt-related developmental program. PLoS Genet. 4, e10 (2008).

12. Geserick, C. \& Blasco, M. A. Novel roles for telomerase in aging. Mech. Ageing Dev. 127, 579-583 (2006).

13. Stewart, S. A. et al. Telomerase contributes to tumorigenesis by a telomere length-independent mechanism. Proc. Natl Acad. Sci. USA 99, 12606-12611 (2002).

14. Sarin, K. Y. et al. Conditional telomerase induction causes proliferation of hair follicle stem cells. Nature 436, 1048-1052 (2005).

15. Park, J. I. et al. Telomerase modulates Wnt signalling by association with target gene chromatin. Nature 460, 66-72 (2009)

16. Imamura, S. et al. A non-canonical function of zebrafish telomerase reverse transcriptase is required for developmental hematopoiesis. PLoS One 3, e3364 (2008).

17. Blasco, M. A., Rizen, M., Greider, C. W. \& Hanahan, D. Differential regulation of telomerase activity and telomerase RNA during multi-stage tumorigenesis. Nat. Genet. 12, 200-204 (1996).

18. Cayuela, M. L., Flores, J. M. \& Blasco, M. A. The telomerase RNA component Terc is required for the tumour-promoting effects of Tert overexpression. EMBO Rep. 6, 268-274 (2005).

19. Fragnet, L., Blasco, M. A., Klapper, W. \& Rasschaert, D. The RNA subunit of telomerase is encoded by Marek's disease virus. J. Virol. 77, 5985-5996 (2003).

20. Li, S., Crothers, J., Haqq, C. M. \& Blackburn, E. H. Cellular and gene expression responses involved in the rapid growth inhibition of human cancer cells by RNA interference-mediated depletion of telomerase RNA. J. Biol. Chem. 280, 23709-23717 (2005).

21. Chu, C., Qu, K., Zhong, F. L., Artandi, S. E. \& Chang, H. Y. Genomic maps of long noncoding RNA occupancy reveal principles of RNA-chromatin interactions. Mol. Cell 44, 667-678 (2011).

22. Herbert, B. S., Hochreiter, A. E., Wright, W. E. \& Shay, J. W. Nonradioactive detection of telomerase activity using the telomeric repeat amplification protocol. Nat. Protoc. 1, 1583-1590 (2006).

23. Loynes, C. A. et al. Pivotal Advance: Pharmacological manipulation of inflammation resolution during spontaneously resolving tissue neutrophilia in the zebrafish. J. Leukoc. Biol. 87, 203-212 (2010).

24. Renshaw, S. A. et al. A transgenic zebrafish model of neutrophilic inflammation. Blood 108, 3976-3978 (2006).

25. Hall, C., Flores, M. V., Storm, T., Crosier, K. \& Crosier, P. The zebrafish lysozyme $\mathrm{C}$ promoter drives myeloid-specific expression in transgenic fish. BMC Dev. Biol. 7, 42 (2007).

26. Ellett, F., Pase, L., Hayman, J. W., Andrianopoulos, A. \& Lieschke, G. J. mpeg1 promoter transgenes direct macrophage-lineage expression in zebrafish. Blood 117, e49-e56 (2011).

27. Rhodes, J. et al. Interplay of pu.1 and gata1 determines myelo-erythroid progenitor cell fate in zebrafish. Dev. Cell 8, 97-108 (2005).

28. Anchelin, M. et al. Premature aging in telomerase-deficient zebrafish. Dis. Model Mech. 6, 1101-1112 (2013).

29. Bertrand, J. Y., Cisson, J. L., Stachura, D. L. \& Traver, D. Notch signaling distinguishes 2 waves of definitive hematopoiesis in the zebrafish embryo. Blood 115, 2777-2783 (2010).

30. Burns, C. E., Traver, D., Mayhall, E., Shepard, J. L. \& Zon, L. I. Hematopoietic stem cell fate is established by the Notch-Runx pathway. Genes Dev. 19, 2331-2342 (2005).

31. Ma, D., Zhang, J., Lin, H. F., Italiano, J. \& Handin, R. I. The identification and characterization of zebrafish hematopoietic stem cells. Blood 118, 289-297 (2011).

32. Herbomel, P., Thisse, B. \& Thisse, C. Zebrafish early macrophages colonize cephalic mesenchyme and developing brain, retina, and epidermis through a M-CSF receptor-dependent invasive process. Dev. Biol. 238, 274-288 (2001).

33. Liongue, C., Hall, C. J., O'Connell, B. A., Crosier, P. \& Ward, A. C. Zebrafish granulocyte colony-stimulating factor receptor signaling promotes myelopoiesis and myeloid cell migration. Blood 113, 2535-2546 (2009).

34. Alcaraz-Perez, F., Mulero, V. \& Cayuela, M. L. Application of the dual-luciferase reporter assay to the analysis of promoter activity in Zebrafish embryos. BMC Biotechnol. 8, 81 (2008).

35. Chen, J. L. \& Greider, C. W. Determinants in mammalian telomerase RNA that mediate enzyme processivity and cross-species incompatibility. EMBO J. 22, 304-314 (2003). 
36. Inui, A. Transgenic study of energy homeostasis equation: implications and confounding influences. FASEB J. 14, 2158-2170 (2000).

37. Maddison, K. \& Clarke, A. R. New approaches for modelling cancer mechanisms in the mouse. J. Pathol. 205, 181-193 (2005).

38. Rudmann, D. G. \& Durham, S. K. Utilization of genetically altered animals in the pharmaceutical industry. Toxicol. Pathol. 27, 111-114 (1999).

39. Rochowski, A., Sun, C., Glogauer, M. \& Alter, B. P. Neutrophil functions in patients with inherited bone marrow failure syndromes. Pediatr. Blood Cancer 57, 306-309 (2011).

40. Yel, L., Tezcan, I., Sanal, O., Ersoy, F. \& Berkel, A. I. Dyskeratosis congenita: unusual onset with isolated neutropenia at an early age. Acta Paediatr Jpn 38, 288-290 (1996).

41. Yilmaz, K., Inaloz, H. S., Unal, B. \& Guler, E. Dyskeratosis congenita with isolated neutropenia and granulocyte colony-stimulating factor treatment. Int. J. Dermatol. 41, 170-172 (2002).

42. Berclaz, P. Y. et al. GM-CSF regulates a PU.1-dependent transcriptional program determining the pulmonary response to LPS. Am. J. Respir. Cell Mol. Biol. 36, 114-121 (2007).

43. Berclaz, P. Y., Shibata, Y., Whitsett, J. A. \& Trapnell, B. C. GM-CSF, via PU.1, regulates alveolar macrophage Fcgamma R-mediated phagocytosis and the IL-18/IFN-gamma -mediated molecular connection between innate and adaptive immunity in the lung. Blood 100, 4193-4200 (2002).

44. Dahl, R. et al. Regulation of macrophage and neutrophil cell fates by the PU.1:C/EBPalpha ratio and granulocyte colony-stimulating factor. Nat. Immunol. 4, 1029-1036 (2003).

45. Galloway, J. L., Wingert, R. A., Thisse, C., Thisse, B. \& Zon, L. I. Loss of gatal but not gata2 converts erythropoiesis to myelopoiesis in zebrafish embryos. Dev. Cell. 8, 109-116 (2005)

46. Monteiro, R., Pouget, C. \& Patient, R. The gatal/pu.1 lineage fate paradigm varies between blood populations and is modulated by tiflgamma. EMBO J. $\mathbf{3 0}$, 1093-1103 (2011)

47. Solder, B., Weiss, M., Jager, A. \& Belohradsky, B. H. Dyskeratosis congenita: multisystemic disorder with special consideration of immunologic aspects. A review of the literature. Clin. Pediatr. (Phila) 37, 521-530 (1998).

48. Erduran, E., Hacisalihoglu, S. \& Ozoran, Y. Treatment of dyskeratosis congenita with granulocyte-macrophage colony-stimulating factor and erythropoietin. J. Pediatr. Hematol. Oncol. 25, 333-335 (2003).

49. Alter, B. P., Gardner, F. H. \& Hall, R. E. Treatment of dyskeratosis congenita with granulocyte colony-stimulating factor and erythropoietin. Br. J. Haematol. 97, 309-311 (1997)

50. Oehler, L. et al. Effective stimulation of neutropoiesis with rh G-CSF in dyskeratosis congenita: a case report. Ann. Hematol. 69, 325-327 (1994)

51. Putterman, C., Safadi, R., Zlotogora, J., Banura, R. \& Eldor, A. Treatment of the hematological manifestations of dyskeratosis congenita. Ann. Hematol. 66, 209-212 (1993)

52. Russo, C. L., Glader, B. E., Israel, R. J. \& Galasso, F. Treatment of neutropenia associated with dyskeratosis congenita with granulocyte-macrophage colonystimulating factor. Lancet 336, 751-752 (1990).

53. Goldman, F. D. et al. Characterization of primitive hematopoietic cells from patients with dyskeratosis congenita. Blood 111, 4523-4531 (2008).

54. Westerfield, M. The Zebrafish Book. A Guide for the Laboratory Use of Zebrafish Danio $^{*}$ (Brachydanio) rerio (University of Oregon Press, 2000).

55. Henriques, C. M., Carneiro, M. C., Tenente, I. M., Jacinto, A. \& Ferreira, M. G. Telomerase is required for zebrafish lifespan. PLoS Genet. 9, e1003214 (2013).
56. White, R. M. et al. Transparent adult zebrafish as a tool for in vivo transplantation analysis. Cell Stem Cell 2, 183-189 (2008).

57. Traver, D. et al. Transplantation and in vivo imaging of multilineage engraftment in zebrafish bloodless mutants. Nat. Immunol. 4, 1238-1246 (2003).

58. Kimmel, C. B., Ballard, W. W., Kimmel, S. R., Ullmann, B. \& Schilling, T. F. Stages of embryonic development of the zebrafish. Dev. Dyn. 203, 253-310 (1995).

59. Anchelin, M., Murcia, L., Alcaraz-Perez, F., Garcia-Navarro, E. M. \& Cayuela, M. L. Behaviour of telomere and telomerase during aging and regeneration in zebrafish. PLoS One 6, e16955 (2011).

60. Canela, A., Vera, E., Klatt, P. \& Blasco, M. A. High-throughput telomere length quantification by FISH and its application to human population studies. Proc. Natl Acad. Sci. USA 104, 5300-5305 (2007).

61. van der Sar, A. M. et al. Zebrafish embryos as a model host for the real time analysis of Salmonella typhimurium infections. Cell Microbiol. 5, 601-611 (2003).

62. Thisse, C., Thisse, B., Schilling, T. F. \& Postlethwait, J. H. Structure of the zebrafish snaill gene and its expression in wild-type, spadetail and no tail mutant embryos. Development 119, 1203-1215 (1993).

63. Xie, M. et al. Structure and function of the smallest vertebrate telomerase RNA from teleost fish. J. Biol. Chem. 283, 2049-2059 (2008).

\section{Acknowledgements}

This work was supported by the Spanish Ministry of Science and Innovation (grants BIO2008-01379, BIO2011-23400 and CSD2007-00002 to VM; 05/0087 and PIO6/00369 to M.L.C), the Fundación Séneca-Murcia (grant numbers 04538/GERM/06 to V.M.; 08760/PI/08 to M.L.C). We thank C. Asin-Aguilar and E. Sánchez-Baeza, I. Fuentes and P. Martínez for excellent technical assistance, Drs D. Traver and C. Hall for ISH constructs, Drs P. Crosier, S. Renshaw and G. Lieschke for the transgenic lines, and the Sanger Institute for providing the tert mutant zebrafish line.

\section{Author contributions}

M.L.C. and V.M. devised the study; F.A.-P., J.G.-C., D.G.-M., L.I.Z., M.L.C. and V.M. designed the research; F.A.-P., J.G.-C., D.G.-M., A.L.-M., M.A., J.G.-C., D.A., V.M. and M.L.C. performed the research; F.A.-P., J.G.-C., D.G.-M., A.L.-M., M.A., J.G.-C., D.A., L.I.Z., V.M. and M.L.C. analysed the data, and F.A.-P., L.I.Z., V.M. and M.L.C. wrote the paper.

\section{Additional information}

Supplementary Information accompanies this paper at http://www.nature.com/ naturecommunications

Competing financial interests: The authors declare no competing financial interests

Reprints and permission information is available online at http://npg.nature.com/ reprintsandpermissions/

How to cite this article: Alcaraz-Pérez, F. et al. A non-canonical function of telomerase RNA in the regulation of developmental myelopoiesis in zebrafish. Nat. Commun. 5:3228 doi: $10.1038 /$ ncomms4228 (2014). 